
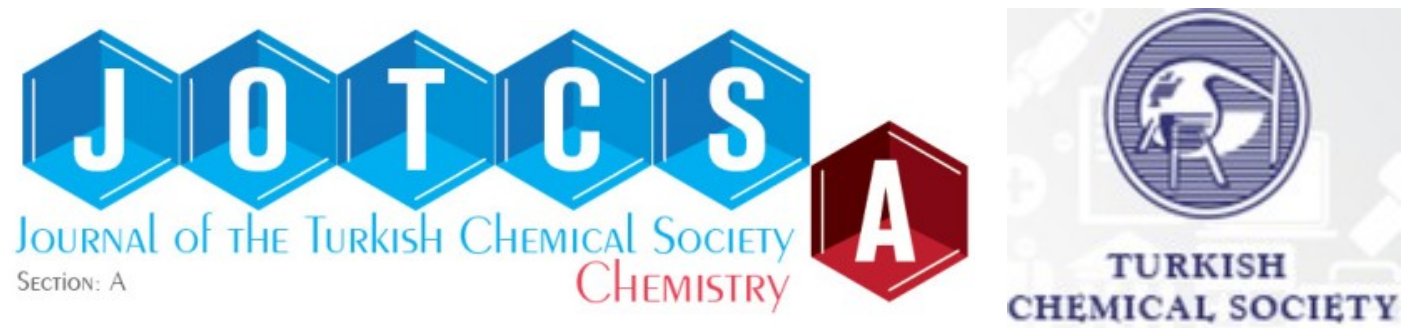

\title{
Corrosion Inhibitive Potentials Of (E)-5-((4-Benzoylphenyl)Diazenyl)-2- Hydroxybenzoic Acid On Mild Steel Surface In 0.5 M HCl- Experimental and DFT Calculations
}

\author{
Justinah Solayide Amoko ${ }^{1,2,4} \square$, Olawale Folorunso Akinyele $\bar{Q}$, \\ Oluwatoba Emmanuel Oyeneyin ${ }^{1,4} \otimes D$, and Samson Dare Olayanju政
}

${ }^{1}$ Department of Chemical Sciences, Adekunle Ajasin University, Akungba-Akoko, Ondo State, Nigeria.

${ }^{2}$ Department of Chemistry, Adeyemi College of Education, Ondo, Ondo State, Nigeria.

${ }^{3}$ Department of Chemistry, Obafemi Awolowo University, Ile-Ife, Nigeria.

${ }^{4}$ Theoretical and Computational Chemistry Unit, Department of Chemical Sciences, Adekunle Ajasin University, Akungba-Akoko, Ondo State, Nigeria.

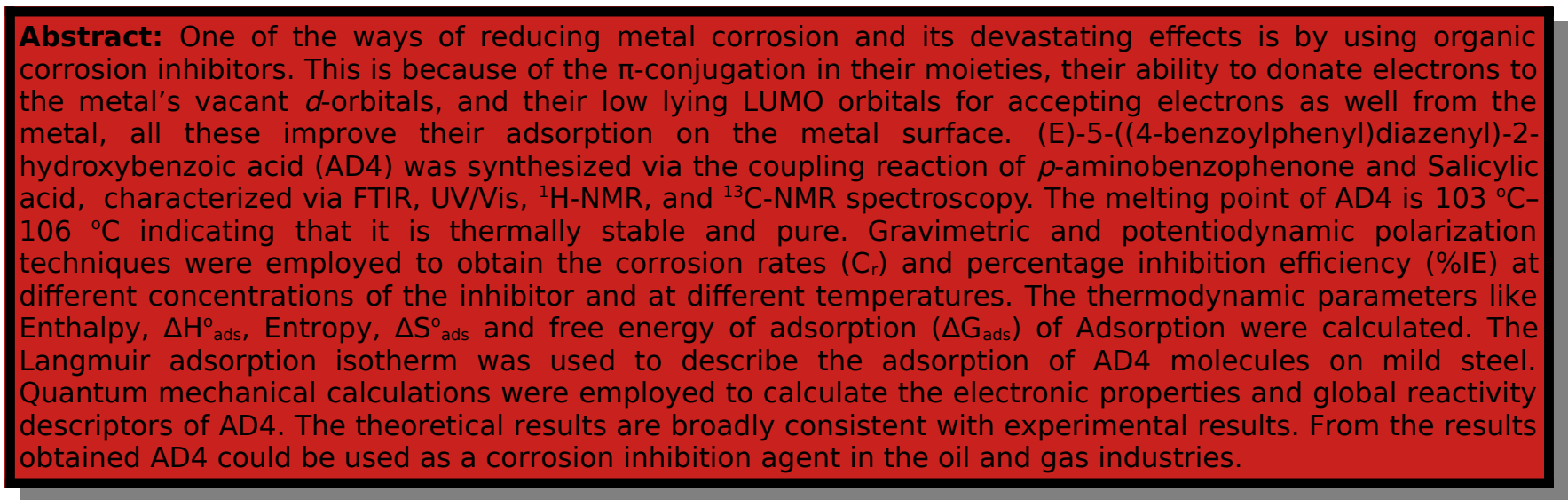

Keywords: Corrosion; Corrosion inhibitors; Adsorption isotherm; Density functional theory; (E)-5-((4benzoylphenyl)diazenyl)-2-hydroxybenzoic acid

Submitted: November 05, 2020. Accepted: January 17, 2021.

Cite this: Amoko JS, Akinyele OF, Oyeneyin OE, Olayanju SD. Corrosion Inhibitive Potentials Of (E)-5-((4Benzoylphenyl)Diazenyl)-2-Hydroxybenzoic Acid On Mild Steel Surface In $0.5 \mathrm{M} \mathrm{HCl}$ - Experimental and DFT Calculations. JOTCSA. 2021;8(1):343-62.

DOI: https://doi.org/10.18596/jotcsa.821488.

*Corresponding author: emmanueltoba90@gmail.com.

\section{INTRODUCTION}

Metals corrode when they come in contact with their environment like those that happen when metal parts come in contact with acids used in acid pickling and descaling (1) in the industries. Loss of lives and properties, increased the cost of production while replacing or repairing damaged parts and reduction in the duration of equipment amongst others are some of the dangers posed by corrosion of metals (2). Also, metallic parts of household equipment like burglary proof, office equipment like tables and chairs, electronic devices, etc would last longer if protected from corrosion. Combating this menace, therefore, is very important, although it is more achievable to reduce it than to total removal. Corrosion occurs when the surface of metals are being attacked by a series of chemical reactions like the formation of oxides (3). Corrosion inhibitors have been employed over the 
past few decades and in recent times to achieve this (4), (5), (6). Heteroatomic organic inhibitors are used because they are usually extensively conjugated, the lone pairs of electrons on the heteroatomic $\mathrm{O}, \mathrm{N}$, and $S$ present in their moieties make available electrons to the metal's vacant $d$-orbitals (7), (8), (9). These inhibitors are adsorbed and as such serve as a protective shield on the surface of the metals, with polar functional groups acting as the reaction centers (10). These organic inhibitors, including azo compounds, are preferred to inorganic salts because they are less toxic. (11), (12). In our previous works, the corrosion inhibitive properties of (E)-3-(2-ptolyldiazenyl)-1-nitrosonaphthalen-2-ol (13) and (E)4-hydroxy-3-[(2,4,6 tribromophenyl)diazenyl $]$ benzaldehyde (5) were investigated, both were adsorbed on the surface of the metal and reduced the rates of corrosion. Quantum mechanical calculations have been employed in conjunction with experimental techniques in a bid to get clearer pictures about the mode and mechanisms of reactions and chemical processes (10), (8), (14). They have also been used as a guide to experiments, predictive tools for reactions and to obtain molecular properties of existing and hypothetical molecular entities (15), (16), (17), (18). Against this background, (E)-5-((4- benzoylphenyl)diazenyl)-2-hydroxybenzoic acid (Scheme 1) was synthesized and characterized using the Fourier transform infrared (FTIR). Ultraviolet/visible (UV/Vis), Nuclear magnetic resonance $\left({ }^{1} \mathrm{H}-\mathrm{NMR}\right.$ and $\left.{ }^{13} \mathrm{C}-\mathrm{NMR}\right)$ spectroscopic techniques and melting point determination. The investigation of corrosion inhibition was carried out, using gravimetric and potentiodynamic polarization techniques. The surface of the metal was characterized using scanning electron microscopy (SEM). The electronic properties and reactivity descriptors were calculated using the density functional theory (DFT) method. The results obtained were compared to experimental results.

\section{EXPERIMENTAL}

\section{Synthesis of (E)-5-((4-benzoylphenyl) diazenyl)-2-hydroxybenzoic acid (AD4)}

All reagents and solvents used are of analytical grade, purchased, and used as supplied. Compound AD4 was synthesized by $p$-aminobenzophenone and coupling it with Salicylic acid (Scheme 1), following the same procedure described for NAD (13) with the same molar ratio of the reagents to give brick red solid. Melting point $103^{\circ} \mathrm{C}-106^{\circ} \mathrm{C}$, yield $41 \%$. Other physical properties are presented in Table 1.<smiles>Nc1ccc(C(=O)c2ccccc2)cc1</smiles><smiles>O=[N+][O-]</smiles><smiles>Cl[GaH]</smiles><smiles>N#[N+]c1ccc(C(=O)c2ccccc2)cc1</smiles><smiles>N#[N+]c1ccc(C(=O)c2ccccc2)cc1</smiles><smiles>O=C(O)c1ccc(N=Nc2ccc(O)c(C(=O)c3ccccc3)c2)cc1</smiles>

Scheme 1: Synthesis of AD4.

Table 1: Physical Properties of AD4.

\begin{tabular}{cccccc}
\hline compound & molecular formula & molecular weight & color & melting point ( $\left.{ }^{\circ} \mathbf{C}\right)$ & \%yield \\
\hline $\mathrm{AD4}$ & $\mathrm{C}_{20} \mathrm{H}_{14} \mathrm{~N}_{2} \mathrm{O}_{4}$ & 346.342 & Brick Red & $103-106$ & 41 \\
\hline
\end{tabular}

\section{Spectral Measurements}

\section{Infrared spectra}

The Infrared spectra (using $\mathrm{KBr}$ disc) of AD4 were recorded on Shimadzu FTIR 8000 Spectrometer at the Redeemer's University, Ede, Nigeria (Supp. 1, Table 2). The IR spectrum in Figure 1 showed a band at $3435 \mathrm{~cm}^{-1}$ which is attributed to $\mathrm{VO}-\mathrm{H}_{\mathrm{str}}$, while the band at $3061 \mathrm{~cm}^{-1}$ is for $V C-H_{\text {str }}\left(\right.$ aromatic $\left.\mathrm{sp}^{2}\right)$, band at $1600 \mathrm{~cm}^{-1}$ is assigned to $V C=C_{\text {str }}$, band at 1448 $\mathrm{cm}^{-1}$ assigned to $v N=N_{\text {str }}$, band at $1678 \mathrm{~cm}^{-1}$ is assigned to $v C=\mathrm{O}_{\text {str }}$ and band at $1296 \mathrm{~cm}^{-1}$ is assigned to $V C-\mathrm{O}_{\text {str. }}$. The spectrum showed the expected functional groups especially the azo ($\mathrm{N}=\mathrm{N}-$ ), aromatic $-\mathrm{C}=\mathrm{C}-,-\mathrm{C}=\mathrm{O}-$ and the hydroxyl groups (Table 2 ), signifying the formation of the dye. 
Table 2: Important IR Absorption Bands $\left(\mathrm{cm}^{-1}\right)$ of AD4.

\begin{tabular}{ccccccc}
\hline Compound & OH str & $\mathbf{- C H}$ & $\mathbf{- C}=\mathbf{C}-$ & $\mathbf{- N = N -}$ & $\mathbf{- C}=\mathbf{O}-\mathbf{s t r}$ & $\mathbf{- C}-\mathbf{O}-\mathbf{s t r}$ \\
\hline AD4 & 3435 & 3061 & 1600 & 1448 & 1678 & 1296 \\
\hline
\end{tabular}

\section{Electronic spectra}

The electronic spectra of AD4 were determined in ethanol using Shimadzu UV-Vis Spectrometer at the Central Laboratory Science, Obafemi Awolowo University, Ile-Ife, Osun State, Nigeria (Supp. 2,
Table 3). The UV/Visible spectrum (Figure 2) showed peaks at $280 \mathrm{~nm}, 325 \mathrm{~nm}, 380 \mathrm{~nm}$ attributed to $\pi-$ $\pi^{*}$ aromatic, $\pi-\pi^{*}$ (IMCT from the entire molecule via the $-\mathrm{N}=\mathrm{N}$ - group), and $\mathrm{n}-\pi^{*}$ (from the heteroatoms present in the molecule), respectively.

Table 3: Electronic spectra data of AD4.

\begin{tabular}{cc} 
Compound & $\boldsymbol{\lambda}_{\max }(\mathbf{n m})$ \\
\hline AD4 & $280,325,380$
\end{tabular}

\section{Assignment}

$\pi-\pi^{*}$ aromatic, $\pi-\pi^{*}(\mathrm{IMCT})$ and $n-\pi^{*}$ respectively

\section{Nuclear Magnetic Resonance spectra}

The NMR of AD4 was recorded in dimethyl sulfoxide (DMSO) $\mathrm{C} /$ Bruker Avance $400 \mathrm{MH}_{\mathrm{z}}$ using deuterated solvents and tetramethyl silane (TMS) as an internal standard at the Department of Chemistry, FriedrichSchiller University, Jena, Germany (Supp. 3 and 4, Table 4). The Signal at $3.40 \mathrm{ppm}$ for the ${ }^{1} \mathrm{H}$ NMR spectrum is due to hydroxyl proton, $H_{a}$ of the carboxylic acid group (Figure 3 and Table 4) while the peak at $11.50 \mathrm{ppm}$ is due to the proton on the free hydroxyl group, $\mathrm{H}_{\mathrm{b}}$. The Signals at $7.50-9.50$ ppm are attributed to the different protons of the phenyl rings. The ${ }^{13} \mathrm{C}$ NMR spectrum (Figure 4) showed signals at 118, 119, 123, 127-129, 132, 134, $136,137,138,150,161,191$, and 197 ppm corresponding to different carbons in the molecule, with 136 for carbonyl carbon and 191 for carboxylic acid carbon.

\section{Materials and method for corrosion studies}

\section{Gravimetric method}

The coupons were weighed. The experiment was conducted in a thermostated water bath with the coupons dipped in $0.5 \mathrm{M} \mathrm{HCl}(100 \mathrm{~mL})$ test solutionsone without the inhibitor AD4 (blank), and the others with different concentrations of AD4 (2.89 x 10-4 $\left.1.444 \times 10^{-3} \mathrm{M}\right)$ for 6 hours and at different temperatures $(298-338 \mathrm{~K})$. The metals were recovered from the test solutions, rinsed with acetone, dried and reweighed. This experiment was done in triplicate to ensure consistency in the results obtained. Equations 1-3 were obtained from the resulting data (Table 4 ).

$$
\begin{gathered}
C_{R}=\frac{W_{0}-W_{1}}{A_{t}} \\
\theta=1-\frac{C_{r}^{I}}{C_{r}^{0}}
\end{gathered}
$$

$C_{R}$ is the corrosion rate, $\theta$, the degree of freedom and \%IE, the percentage inhibition efficiency of AD4. $\mathrm{W}_{0}$ (weight loss in the blank solution), $\mathrm{W}_{1}$ (weight loss of mild steel with the inhibitor) in grams. A (area in $\mathrm{cm}^{2}$ ), $\mathrm{t}$ (time in $\mathrm{hrs}$ ). $\mathrm{C}_{\mathrm{r}} \mathrm{i}$ (rate of corrosion with inhibitor), and $\mathrm{C}_{\mathrm{r}} \mathrm{O}$ (rate of corrosion without inhibitor) in $\mathrm{g} \mathrm{cm}^{-2} \mathrm{~h}^{-1}$.
The Langmuir adsorption isotherm (Eq. 4) was employed to describe the mode of adsorption of AD4 on the surface of the metal.

$$
\frac{C}{\theta}=\left[\frac{1}{K_{a d s}}\right]+C
$$

With $C$ being the concentration of AD4, Kads, the equilibrium adsorption constant and $\theta$, the extent of surface coverage. The thermodynamic parameters were also calculated to further explain the adsorption process. The standard Gibb's free energies of adsorption ( $\Delta \mathrm{G}^{0}$ ads) were calculated in equation 5 .

$$
K_{a d s}=\frac{1}{55} e^{\frac{-\Delta G_{a d s}^{o}}{R T}}
$$

$\Delta \mathrm{G}_{\mathrm{ads}}$ are the free energy of adsorption, $\mathrm{R}$ being the gas constant, and 55.5, the isocratic contribution of water in the solution. The enthalpy, $\Delta \mathrm{H}^{0}$ and entropy $\Delta \mathrm{S}^{0}$ were obtained from the plots of $\Delta \mathrm{G}^{0}$ ads against temperature (Equation 6).

$$
\Delta G_{a d s}^{o}=\Delta H^{o}-T \Delta S^{o}
$$

This was accompanied by the kinetic model which was used to obtain the activation energies, Ea, and the pre-exponential factors from the plot of $\mathrm{InCr}$ against $1 / T$ (Figure 9) with the application of the Arrhenius equations 7 and 8, as presented in Table 5.

$$
\begin{gathered}
C_{R}=A \times e^{\frac{-E_{a}}{R T}} \\
\ln C_{R}=\ln A-\frac{E_{a}}{R T}
\end{gathered}
$$

Enthalpy, $\Delta \mathrm{H}^{*}$ and entropy, $\Delta \mathrm{S}^{*}$ of activation values were calculated (Equation 8) and Table 6.

$$
C_{R}=\left(\frac{R T}{N h}\right) \exp \left(\frac{\Delta S^{0}}{R}\right) \exp \left(\frac{-\Delta H^{0}}{R T}\right)
$$


$\mathrm{h}$ is the Planck's constant, $\mathrm{N}$ the Avogadro's number, $\mathrm{T}$ the absolute temperature, and $\mathrm{R}$ the universal gas constant.

\section{Potentiodynamic polarization technique}

This experiment was conducted as it was in (13). The \%IE was calculated from the data extracted from the Tafel curves (Equation 10).

$$
\% I E=\frac{I_{c o r r}^{0}-I_{c o r r}}{I_{c o r r}^{0}} \times 100
$$

where, $\mathrm{I}^{0}$ corr and $\mathrm{I}_{\text {corr }}$ are the corrosion densities in the absence and presence of the inhibitor, respectively.

\section{Surface morphology}

The surface architecture of the mild steel before and after immersion in acid solution (both in the blank and inhibitor solutions) was imaged using Scanning Electron Microscope (SEM) Phenom Prox by Phenomworld Eindhoven, The Netherlands.

\section{Quantum chemical calculations}

Quantum chemical calculations were carried out with complete geometric optimization on the best conformer (obtained by the molecular mechanics' force field) using DFT with a large polar 6-31G* basis set for all atoms (19). Electronic properties such as the energies of the frontier molecular orbitals, FMOs [energies of the highest occupied molecular orbital ( $\left.E_{\text {номо }}\right)$ and energy of the lowest unoccupied molecular orbital $\left.\left(E_{\text {Lumo }}\right)\right]$, ionization potential (I) in equation 11 , electron affinity $(A)$ in equation 12 energy bandgap $\left(E_{g}\right)$ in equation 13 , global reactivity descriptors like chemical hardness $(n)$ in equation 14 , softness $(\delta)$ in equation 15 , electronegativity $(\chi)$ in equation 16 , chemical potential $\left(C_{P}\right)$ in equation 17, global electrophilicity index $(\omega)$ in equation 18 and the fraction of electrons transferred $(\Delta N)$ in equation 19 were calculated, all on Spartan 14 computational chemistry software (20). The FMOs maps of AD4 were also plotted together with its electrostatic potential map.

$$
\begin{aligned}
& \mathrm{I}=-\mathrm{E}_{\text {Hомо }} \\
& \mathrm{A}=-\mathrm{E}_{\text {LUMо }} \\
& \mathrm{E}_{\mathrm{g}}=\mathrm{E}_{\text {LUMO }}-\mathrm{E}_{\text {Hомо }} \\
& \eta=\frac{\Delta E}{2} \\
& \delta=\frac{1}{\eta} \\
& \chi=\frac{(I+A)}{2} \\
& \mathrm{C}_{\mathrm{P}}=-\chi \\
& \omega=\frac{\chi^{2}}{E_{g}}
\end{aligned}
$$

$$
\Delta \mathrm{N}=\frac{X_{F e}-X_{i n h}}{2\left(\eta_{F e}+\eta_{i n h}\right)}
$$

To account for the directions of electrons flow (predicting electrophilic and nucleophilic atoms), the Fukui parameters were calculated using a dual descriptor (defined within $[-1 ; 1]$ ) to determine individual sites within the molecule (7) (equations 20 and 21 ).

$$
f_{k}^{+}=\left[q_{k}(N+1)-q_{k} N\right]_{\text {for nucleophilic attack (Eq. }}^{\text {for }}
$$

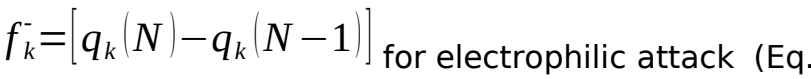
21)

$$
\Delta f_{k}(r)=f_{k}^{+}-f_{k}^{-}
$$

$q_{k}(N+1)$ is the charges on the atoms in the molecule's anionic $(\mathrm{N}+1)$ state, $\mathrm{q}_{\mathrm{k}}(\mathrm{N})$ is the charges on the atoms in the molecule's neutral $(\mathrm{N})$ state and $q_{k}(\mathrm{~N}-1)$ is the charges on the atoms in the molecule's cationic (N-1) state (equations 20-22). $\mathrm{F}_{\mathrm{k}}{ }^{+}$ and $f_{k}$ are the nucleophilic and electrophilic Fukui functions, respectively.

\section{RESULTS AND DISCUSSION}

\section{Gravimetric analysis}

\section{Variation of IE with Concentration and Temperature}

The data obtained for the gravimetric experiments are recorded in Table 4 . The variations of the \%IE with concentration and temperature were considered. Generally, \%IE increases with an increase in concentration while it decreases as the temperature increases (Table 4 and Figures 5 and $6)$. This is expected because as more of the inhibitor is used (increased concentration), more of its molecules are adsorbed on the metal surface thereby reducing the rate of corrosion. Also, as we move to higher temperatures, some of the inhibitor molecules are easily desorbed, thereby decreasing the inhibition efficiency. The optimum adsorption took place at $318 \mathrm{~K}$ where a \%IE of 95 was observed, beyond this there is desorption of AD4 molecule at the metal's surface. This was also observed by previous researchers (21) and in our previous works (5). The \%IE of 4,5,6,7-tetrahydro1,3-benzothiazole was reported to be $81.53 \%$ by Mallikarjuna and coworkers (12) while it was 80.39 \%in our previous work with (E)-4-hydroxy-3-[(2,4,6tribromophenyl)diazenyl]benzaldehyde (5). 
Table 4: ${ }^{1} \mathrm{HNMR}$ and ${ }^{13} \mathrm{CNMR}$ spectral data of AD4 in DMSO.

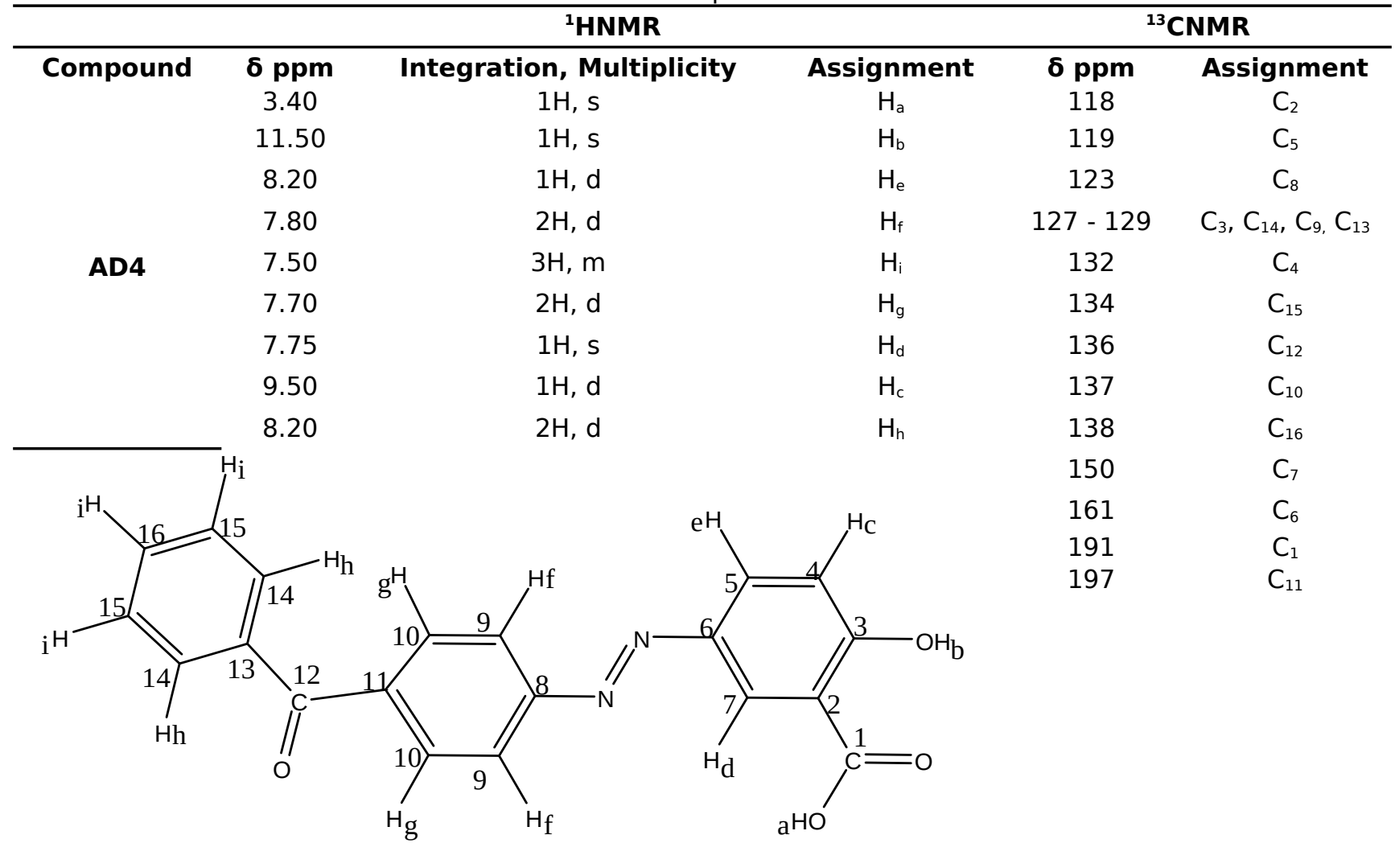

(E)-5-((4-benzoylphenyl)diazenyl)-2-hydroxybenzoic acid (AD4), $\mathrm{d}=$ doublet, $\mathrm{s}=$ singlet, $\mathrm{m}=\mathrm{multiplet}$

\section{Adsorption Considerations}

and

Thermodynamic

A plot of $C / \theta$ vs $C(298-338 \mathrm{~K})$ generated the data in Table 6 and their plots (Figure 7). The adsorption obeys the Langmuir adsorption isotherm given their $R^{2}$ values. $\Delta G$ values show that the adsorption process is spontaneous (Table 6), these values are between -28 to $-36 \mathrm{~kJ} / \mathrm{mol}$, indicating that the adsorption of AD4 molecules on the mild steel is through physiosorption. The value of $\Delta S$ obtained ($0.101 \mathrm{~kJ} / \mathrm{mol}$ ) showed the molecules or AD4 are not as free to move as they are being trapped on the surface of the metal. The positive value of $\Delta \mathrm{H}^{0}$ ads obtained indicated an endothermic reaction. $\Delta \mathrm{H}^{0}$ ads around $-40 \mathrm{kJmol}^{-1}$ is a physisorption process while it is a chemisorption process when it tends to -100 $\mathrm{kJmol}^{-1}$. The adsorption of AD4 a physiosorption process $\left(\Delta \mathrm{H}_{\text {ads }}^{0}=0.14 \mathrm{kJmol}^{-1}\right)$.
Values of apparent activation energies may increase in the presence of AD4 than that of a pure acidic medium, if it is so like it is in this work, it implies that the AD4 is absorbed physically (physisorption) (22). The larger values of A in the presence of AD4 compared to that of the blank solution (Table 7) implied that most of the active sites are blocked by AD4.

The larger $\Delta \mathrm{H}^{*}$ and $\Delta \mathrm{S}^{*}$ values in the presence of AD4 (Table 8 ) is a consequence of the increase in energy barrier of the corrosion process in the presence of AD4 as also seen from the activation energies, Ea. The interaction of AD4 and mild steel is endothermic in nature, owing to the positive $\Delta \mathrm{H}^{*}$ values in the blank and in the presence of AD4 while the negative $\Delta S^{*}$ values implied that there is the formation of the activated complex in the ratedetermining step which is dissociative, hence an observable increase in disorderliness (23). 
Table 5: Parameters obtained from gravimetric analysis.

\begin{tabular}{|c|c|c|c|c|c|c|}
\hline Compound & Temp. (K) & Concentration (M) & Weight loss (g) & Corrosion rate $\left(\mathrm{gcm}^{-2} \mathrm{~h}^{-1}\right)$ & \%IE & $\boldsymbol{\theta}$ \\
\hline \multirow{30}{*}{ AD4 } & \multirow{6}{*}{298} & Blank & 0.041 & 0.00213 & - & - \\
\hline & & 0.000289 & 0.0180 & 0.0011 & 50 & 0.4947 \\
\hline & & 0.000577 & 0.0150 & 0.0008 & 64 & 0.6371 \\
\hline & & 0.000866 & 0.0120 & 0.0007 & 68 & 0.6746 \\
\hline & & 0.001155 & 0.0110 & 0.0007 & 69 & 0.6871 \\
\hline & & 0.001444 & 0.0090 & 0.0005 & 78 & 0.7765 \\
\hline & \multirow{6}{*}{308} & Blank & 0.036 & 0.00209 & - & - \\
\hline & & 0.000289 & 0.0250 & 0.0015 & 29 & 0.2887 \\
\hline & & 0.000577 & 0.0210 & 0.0013 & 39 & 0.3901 \\
\hline & & 0.000866 & 0.0160 & 0.0008 & 60 & 0.5978 \\
\hline & & 0.001155 & 0.0120 & 0.0007 & 65 & 0.6515 \\
\hline & & 0.001444 & 0.0118 & 0.0007 & 67 & 0.6701 \\
\hline & \multirow{6}{*}{318} & Blank & 0.048 & 0.00253 & - & - \\
\hline & & 0.000289 & 0.0230 & 0.0012 & 52 & 0.5241 \\
\hline & & 0.000577 & 0.0100 & 0.0006 & 78 & 0.7791 \\
\hline & & 0.000866 & 0.0090 & 0.0005 & 80 & 0.7967 \\
\hline & & 0.001155 & 0.0080 & 0.0005 & 81 & 0.8046 \\
\hline & & 0.001444 & 0.0020 & 0.0001 & 95 & 0.9540 \\
\hline & \multirow{6}{*}{328} & Blank & 0.061 & 0.00312 & - & - \\
\hline & & 0.000289 & 0.0370 & 0.0022 & 29 & 0.2869 \\
\hline & & 0.000577 & 0.0370 & 0.0019 & 38 & 0.3751 \\
\hline & & 0.000866 & 0.0210 & 0.0013 & 59 & 0.5909 \\
\hline & & 0.001155 & 0.0160 & 0.001 & 69 & 0.6850 \\
\hline & & 0.001444 & 0.0140 & 0.0008 & 74 & 0.7494 \\
\hline & \multirow{6}{*}{338} & Blank & 0.15 & 0.00912 & - & - \\
\hline & & 0.000289 & 0.0310 & 0.0016 & 83 & 0.4887 \\
\hline & & 0.000577 & 0.0220 & 0.0013 & 85 & 0.5731 \\
\hline & & 0.000866 & 0.0200 & 0.0012 & 87 & 0.6080 \\
\hline & & 0.001155 & 0.0240 & 0.0013 & 86 & 0.5923 \\
\hline & & 0.001444 & 0.0200 & 0.0012 & 87 & 0.6168 \\
\hline
\end{tabular}




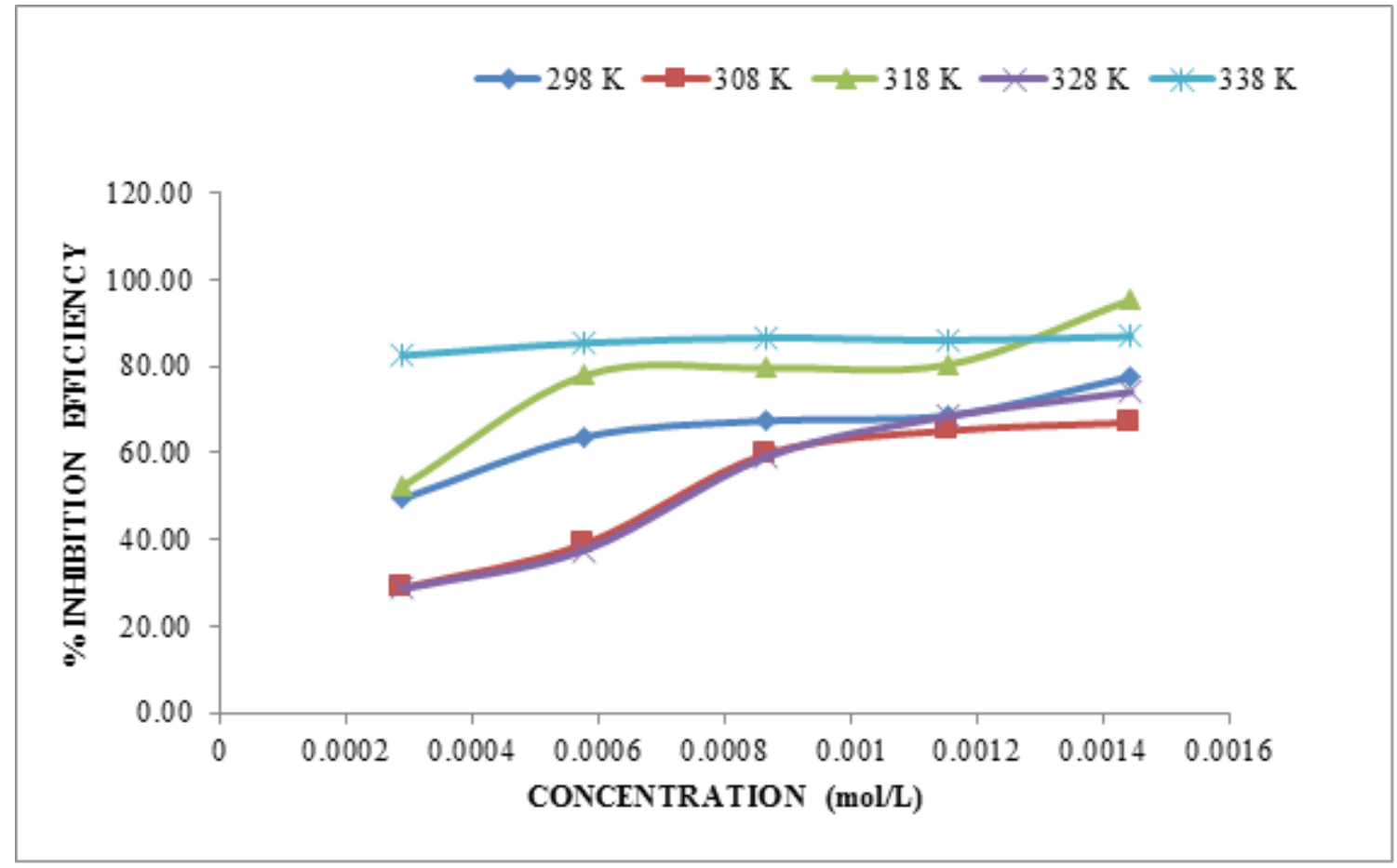

Figure 5: Variation of IE of AD4 with concentration.

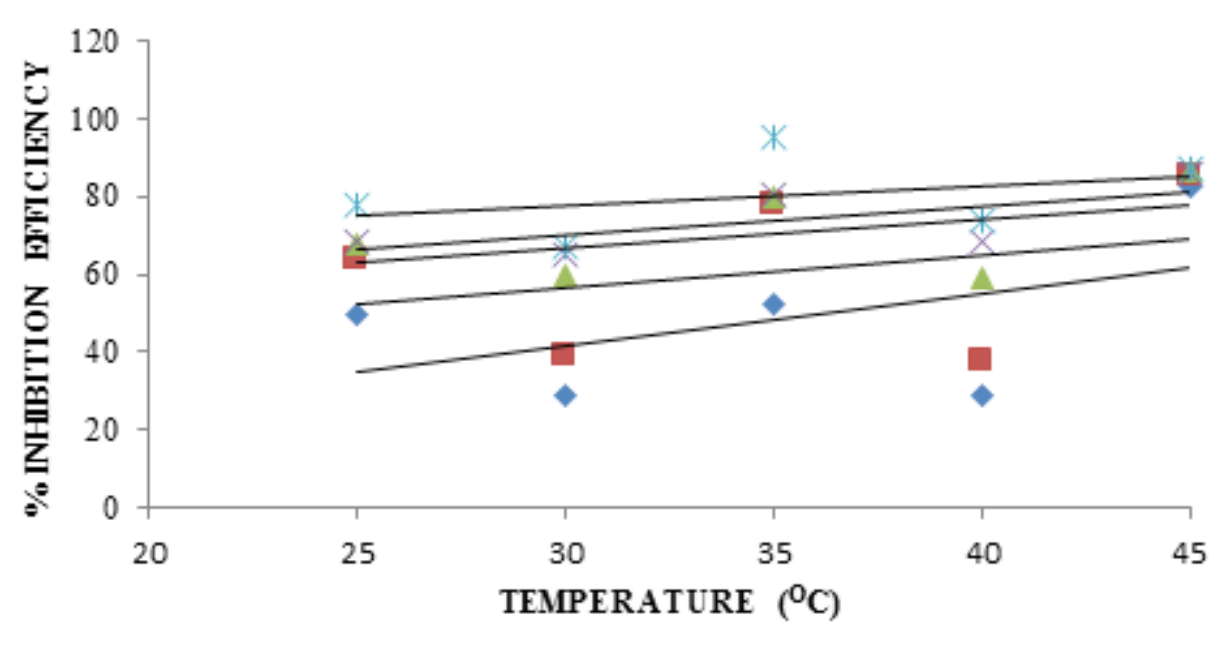

$\checkmark 100$ PPM

200 PPM

$\triangle 300 \mathrm{PPM}$

$\times 400$ PPM

Ж500 PPM

Figure 6: Variation of IE of AD4 with temperature. 


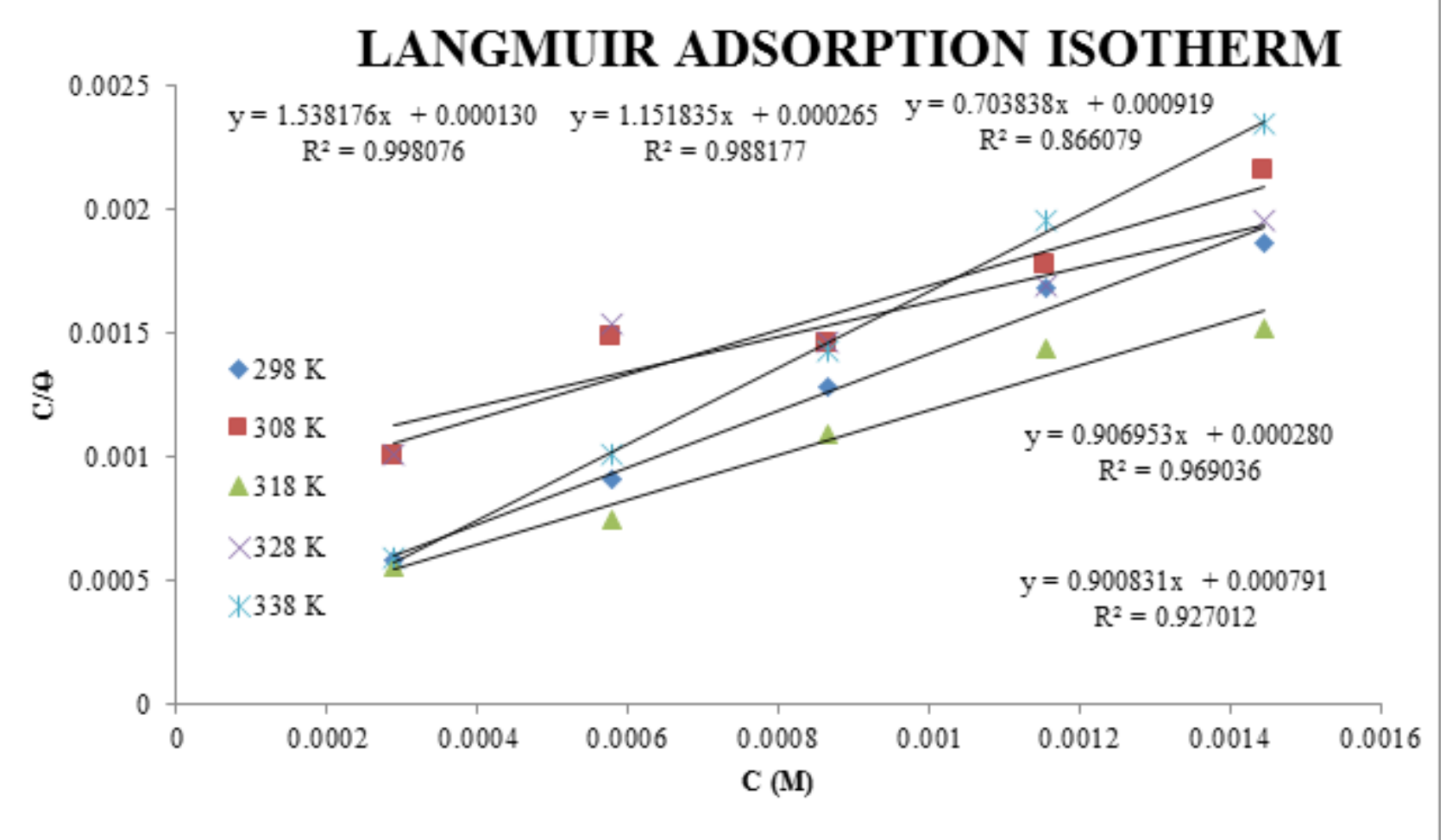

Figure 7: Langmuir isotherm for AD4 adsorption.

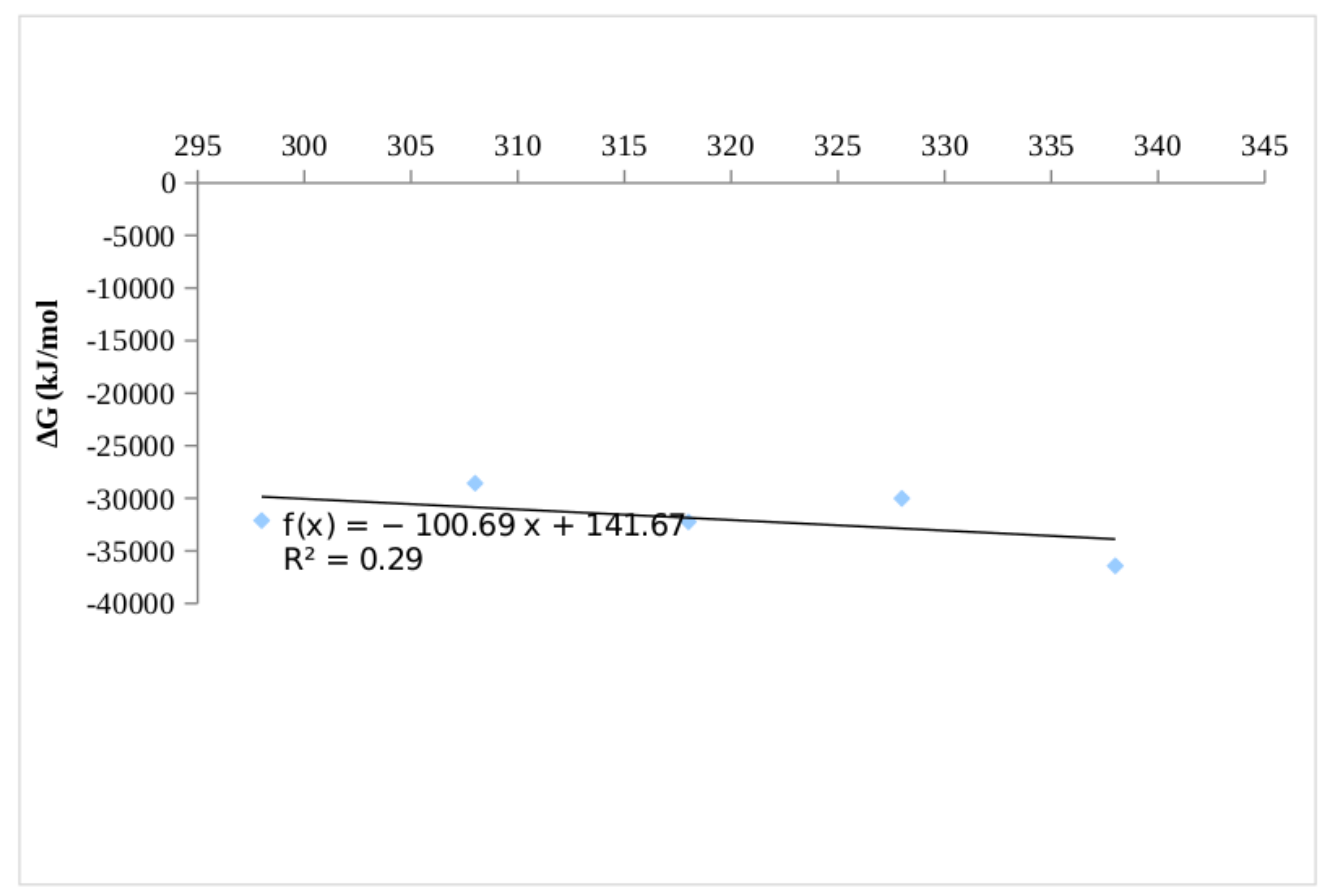

Figure 8: Determination of $\Delta \mathrm{H}^{\circ}$ ads and $\Delta \mathrm{S}^{\circ}$ ads, of $A D 4$. 
Table 6: Thermodynamic parameters of AD4.

\begin{tabular}{|c|c|c|c|c|c|c|c|}
\hline Comp. & Temp. (K) & $\mathbf{R}^{2}$ & Intercept & $\mathbf{K}$ & $\Delta G\left(\mathrm{kJmol}^{-1}\right)$ & $\Delta S\left(\mathrm{~kJ} / \mathrm{mol}^{-1} \mathrm{~K}^{-1}\right)$ & $\Delta \mathrm{H}\left(\mathrm{kJmol}^{-1}\right)$ \\
\hline \multirow{5}{*}{ AD4 } & 298 & 0.9981 & 0.00013 & 7692.31 & -32.120 & -0.10069 & 0.14167 \\
\hline & 308 & 0.927 & 0.000791 & 1264.22 & -28.578 & & \\
\hline & 318 & 0.969 & 0.00028 & 3571.43 & -32.247 & & \\
\hline & 328 & 0.8661 & 0.000919 & 1088.14 & -30.020 & & \\
\hline & 338 & 0.9981 & 0.00013 & 7695.31 & -36.432 & & \\
\hline
\end{tabular}

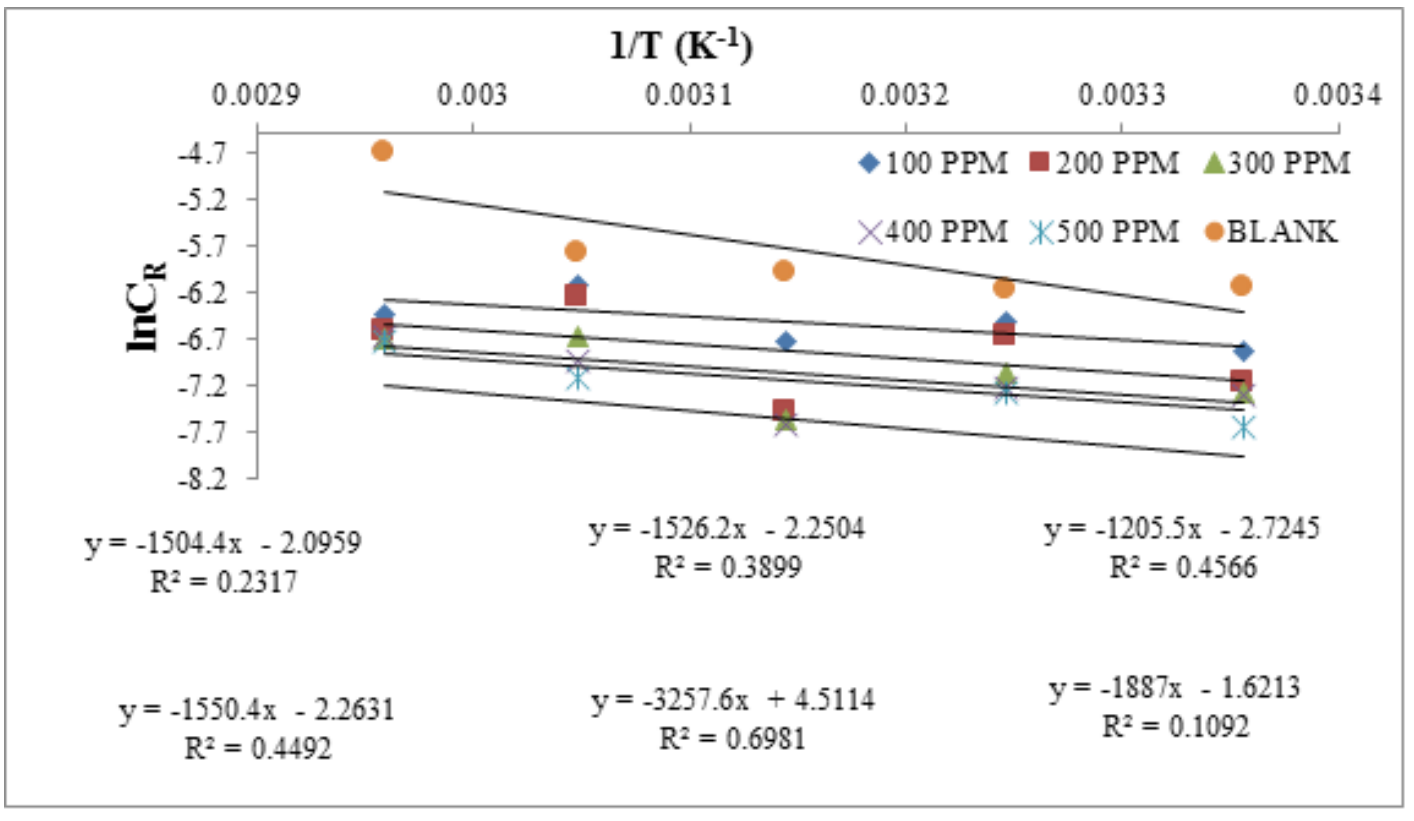

Figure 9: Activation energy plot. 


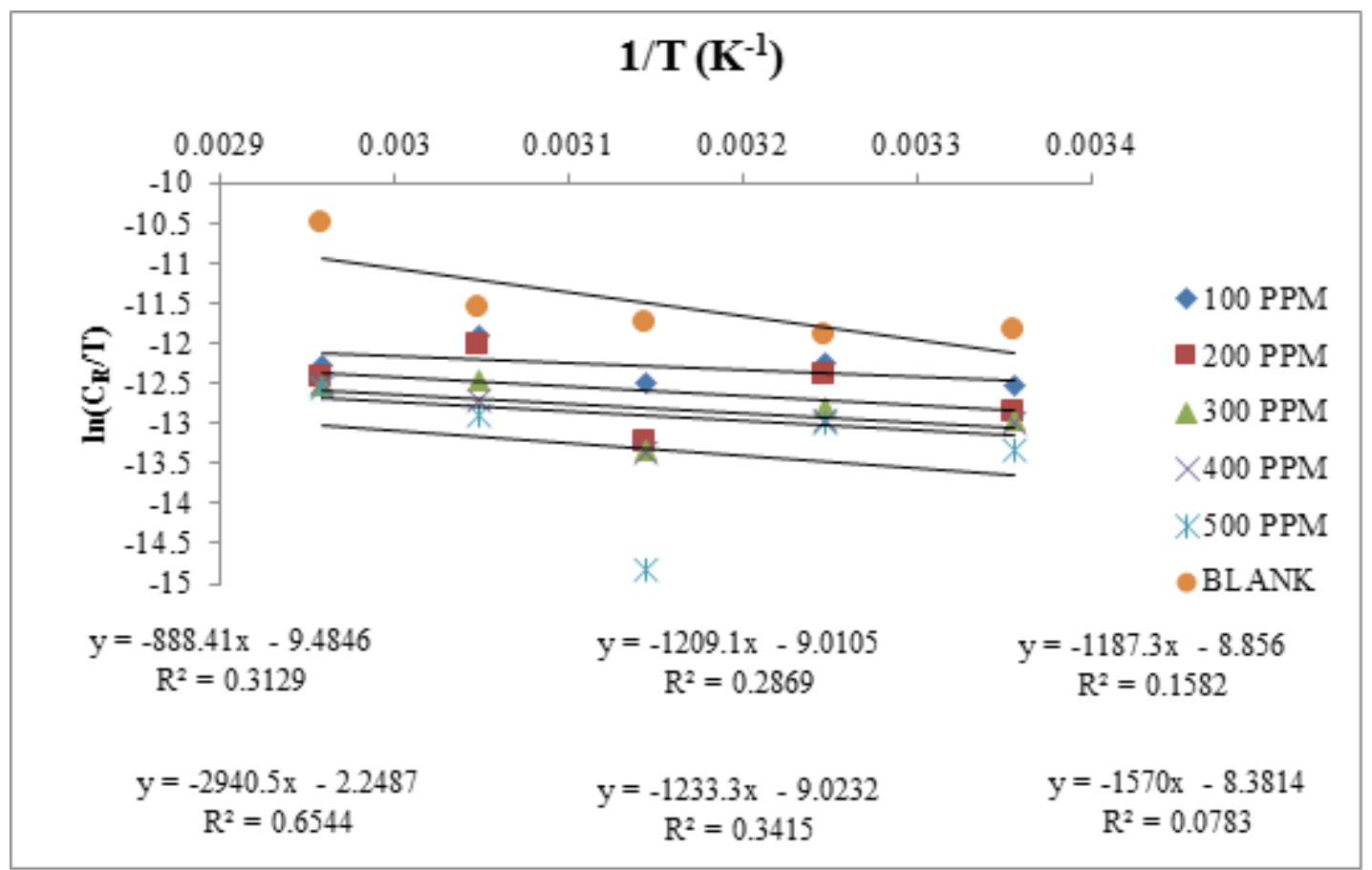

Figure 10: Transition state determination.

Table 7: Activation energy and pre-exponential factor for the process .

\begin{tabular}{cccccc}
\hline Compound & Concentration(M) & Slope & Ea $\left(\mathbf{J m o l}^{-1}\right)$ & In A & A \\
\hline \multirow{4}{*}{ AD4 } & BLANK & -3257.6 & 27078.69 & 4.5114 & 91.05 \\
& 0.000289 & -1205.5 & 10022.53 & 2.7245 & 0.656 \\
& 0.000577 & -1504.4 & 12507.58 & 2.0959 & 0.1230 \\
& 0.000866 & -1526.2 & 12688.83 & 2.2504 & 0.1054 \\
& 0.000116 & -1550.4 & 12890.03 & 2.2631 & 0.1040 \\
& 0.000144 & -1887.0 & 15688.52 & 1.6213 & 0.1976 \\
\hline
\end{tabular}

Table 8: Values for the transition state parameters

\begin{tabular}{clllll}
\hline Compound & \multicolumn{2}{l}{ Concentration (M) } & Slope & Intercept & Enthalpy(Jmol \\
& & & & & Entropy(Jmol \\
\hline & BLANK & -2940.5 & -2.2487 & 24447.4 & -216.236 \\
& 0.000029 & -888.41 & -9.4846 & 7386.241 & -276.395 \\
\multirow{2}{*}{ AD4 } & 0.000058 & -1187.3 & -8.856 & 9871.212 & -271.169 \\
& 0.000087 & -1209.1 & -9.0105 & 10052.457 & -272.453 \\
& 0.000116 & -1233.3 & -9.0232 & 10253.656 & -272.559 \\
& 0.000145 & -1570 & -8.3814 & 13052.980 & -267.223 \\
\hline
\end{tabular}

Tafel plots

AD4 is a mixed-type inhibitor (Fig. 11), that is, it is both cathodic and anodic. The corrosion rate decreases as AD4 concentration increases (Table 9), this is because more of the AD4 molecules covers more surface of the mild steel concentration increases from $0.015 \mathrm{~g}$ to $0.075 \mathrm{~g}$. 


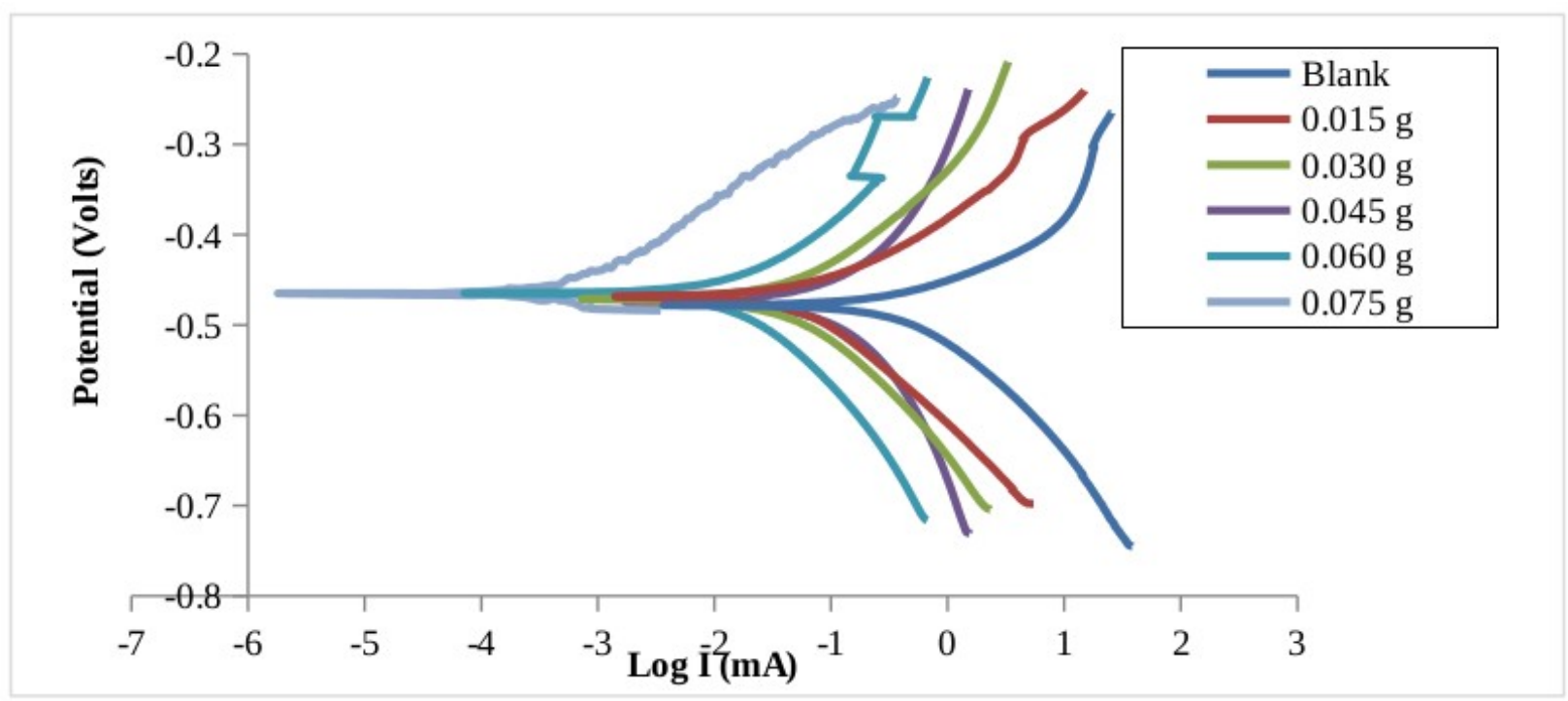

Figure 11: Potentiodynamic polarization curve for AD4 adsorption.

\section{Surface analysis}

The unused mild steel (Figure 11a) showed little or no scratch on its surface, however, Figure $11 \mathrm{~b}$ (mild steel immersed in $0.5 \mathrm{M} \mathrm{HCl}$ for six hours) showed an aggressive attack by the acid. Figure 11c (mild steel in the presence of the inhibitor and acid) is not as smooth as in Figure $11 \mathrm{a}$ but smoother than 11b, this is a consequence of the action of the inhibitor molecule on the surface of the mild steel.

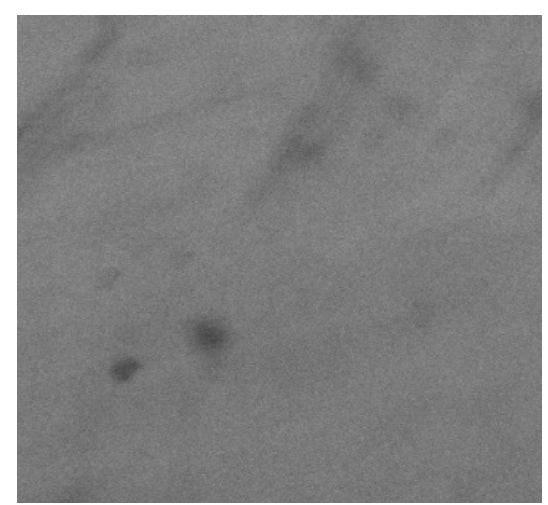

(a)

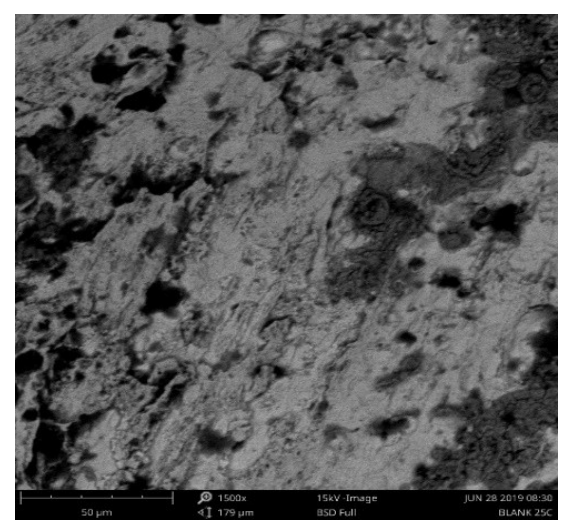

(b)

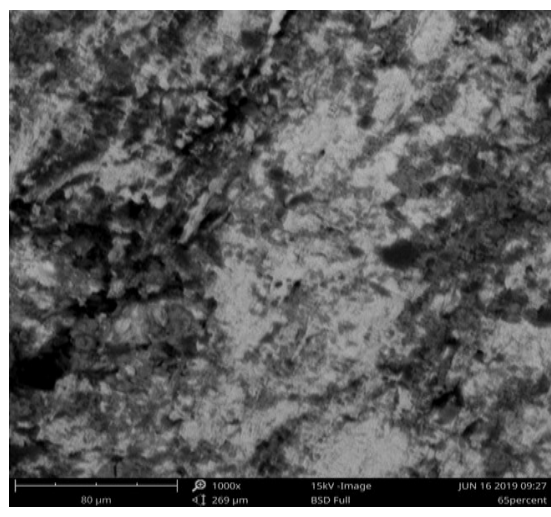

(c)

Figure 12: (a) SEM image of polished mild steel (b) SEM image of mild steel exposed to $0.5 \mathrm{M} \mathrm{HCl}$ (c) SEM image of mild steel in the presence of AD4 molecule. 
Table 9: Polarization Parameters and Inhibition Efficiencies of AD4 on Mild Steel.

\begin{tabular}{|c|c|c|c|c|c|c|c|}
\hline & $\begin{array}{c}\text { Conc. } \\
\text { (g) }\end{array}$ & $-\beta_{c}(m V)$ & $\beta_{\mathrm{a}}\left(\mathrm{mVdec}^{-1}\right)$ & $C_{R} \operatorname{mpy}$ & $\begin{array}{l}-E_{\text {corr }} \\
(\mathbf{m V})\end{array}$ & $I_{\text {corr }}(\mu \mathrm{mA})$ & \%IE \\
\hline \multirow{6}{*}{ AD4 } & Blank & 143.5 & 107.7 & 7.51724 & 478.624 & 740.062 & - \\
\hline & 0.015 & 126.3 & 130.2 & 1.41638 & 501.093 & 139.441 & 81 \\
\hline & 0.030 & 141.7 & 121.3 & 1.33159 & 471.568 & 131.093 & 82 \\
\hline & 0.045 & 189 & 171.8 & 1.14625 & 474.886 & 112.847 & 85 \\
\hline & 0.060 & 159.9 & 152.4 & 0.237362 & 465.244 & 23.368 & 96 \\
\hline & 0.075 & 34.6 & 71.7 & 0.002936 & 464.899 & 0.289 & 99.9 \\
\hline
\end{tabular}

$\mathrm{b}_{\mathrm{c}} \& \mathrm{~b}_{\mathrm{a}}=$ Tafel slopes, $\mathrm{C}_{\mathrm{R}}=\mathrm{b}_{\mathrm{c}} \& \mathrm{~b}_{\mathrm{a}}=$ Tafel slopes, $\mathrm{C}_{\mathrm{R}}=$ corrosion rate, $\mathrm{E}_{\mathrm{corr}}=$ corrosion potential, $\mathrm{I}_{\mathrm{corr}}=$ corrosion current density, IE = inhibition efficiency

\section{Quantum mechanical analysis}

HOMO, LUMO, and $E_{g}$ values of AD4 are presented in Table 10. The low $E_{g}$ value of AD4 suggests that electrons are easily transferred from the compound to the metal surface while the high $\mathrm{E}_{\text {номо }}$ value and low-lying LUMO orbitals indicate that the molecule accepts electrons readily from, while at the same time, donate electrons to the metal's $d$ orbitals, this shows that the mechanism of adsorption here is of electron donation and back-donation as supported by the values of other descriptors calculated. Softness value for example shows that AD4 would react readily with the metal, as also supported by the values of $\chi, \omega$, and $\mu$. The high inhibition efficiency is associated with the electron-donating ability, evidenced by the $\Delta N$ value which is < 3.6 (24), (25). The HOMO plot of AD4 (Fig. 12b) shows that the orbitals with abundant electron spread across the molecule from the carbonyl oxygen $(01)$ to the other part of the molecule, and all the heteroatoms in the process, save for the hydroxyl oxygen on the carboxylic acid group, this shows the part of the molecule donating electrons to the metal, the LUMO (Fig. 12c) orbitals spread over almost the same region as it was in the HOMO map. This confirms that there is an intramolecular charge transfer (ICT) in the molecule. The donor-acceptor (D-A) charge distribution on the electrostatic potential map (Fig. 12d) confirms the charge transfer. These further support the good inhibitory property of AD4. From Table 11, atoms having $f_{k}>0$ are electrophilic while those with $f_{k}<0$ are the nucleophiles. $\mathrm{C} 14$ is the preferred site for the nucleophilic attack as its maximum value of $\mathrm{f}_{\mathrm{k}}{ }^{+}$is 0.036 and positive value of $\Delta f(0.048)$ while $C 5$ is the preferred site for electrophilic attack as it has a maximum value of $f_{k}^{-}(0.002)$ and the negative value of $f_{k}(-0.005)$

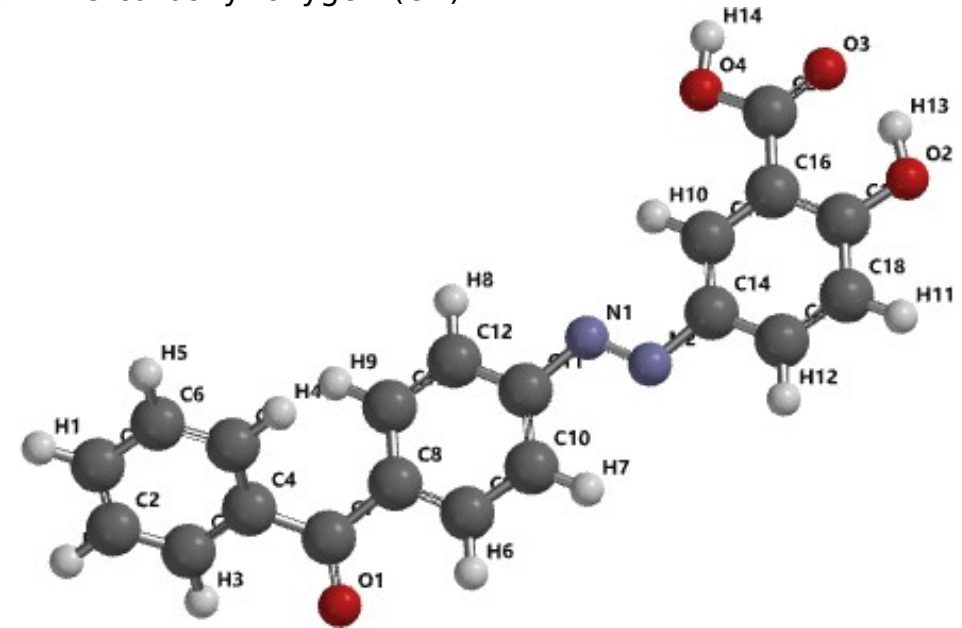

Figure 12a: Optimized structure of AD4. 


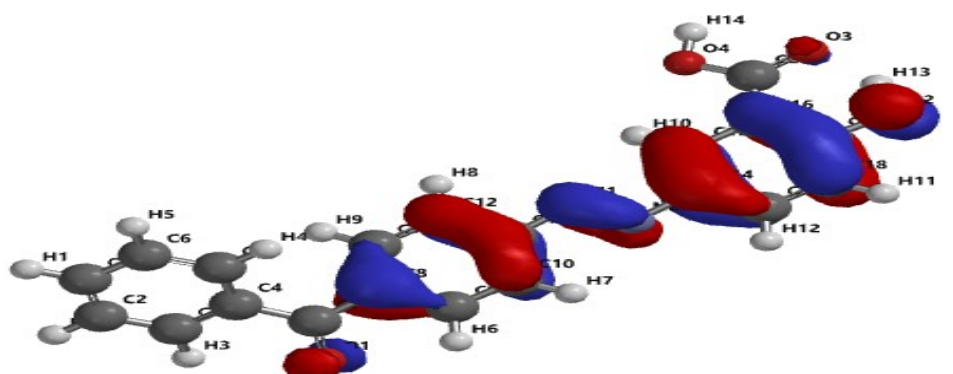

Figure 12b: HOMO map of AD4

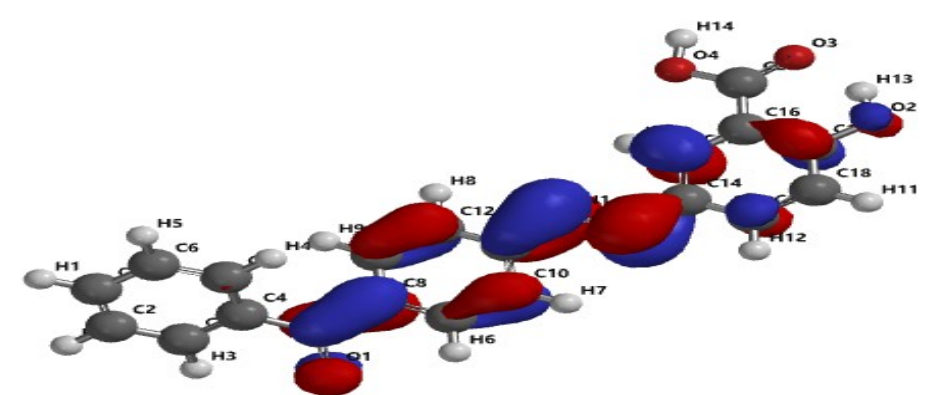

Figure 12c: LUMO map of AD4. 
Table 10: Quantum chemical parameters for AD4 dye.

\begin{tabular}{|c|c|c|c|c|c|c|c|c|c|c|c|}
\hline Parameters & $E_{\text {номо }}(\mathrm{eV})$ & $E_{\text {LUMo }}(\mathrm{eV})$ & $A(e V)$ & I (eV) & $\Delta E(e V)$ & $n(e V)$ & $\delta\left(e V^{-1}\right)$ & $x(e V)$ & $\omega(e V)$ & $\mu(e V)$ & $\Delta \mathbf{N}$ \\
\hline AD4 & -6.12 & -2.58 & 2.58 & 6.12 & 3.54 & 1.77 & 0.56 & 4.35 & 5.35 & 3.64 & 0.75 \\
\hline
\end{tabular}

Table 11: Fukui functions and Mulliken atomic charges of AD4 atoms (excluding hydrogen atoms).

\begin{tabular}{|c|c|c|c|c|c|c|}
\hline AD4 & $\mathbf{q}_{\mathbf{k}} \mathbf{( N + 1 )}$ & $\mathbf{q}_{\mathbf{k}} \mathbf{( N )}$ & $\mathbf{q}_{\mathbf{k}} \mathbf{( N - 1 )}$ & $\mathbf{f}_{\mathbf{k}}{ }^{+}$ & $\mathbf{f}_{\mathbf{k}}{ }^{-}$ & $\mathbf{\Delta}$ \\
\hline C1 & -0.13 & -0.119 & -0.112 & -0.011 & -0.007 & -0.004 \\
\hline C2 & -0.138 & -0.135 & -0.132 & -0.003 & -0.003 & 0 \\
\hline C3 & -0.156 & -0.151 & -0.145 & -0.005 & -0.006 & 0.001 \\
\hline C4 & 0.086 & 0.072 & 0.072 & 0.014 & 0 & 0.014 \\
\hline C5 & -0.18 & -0.177 & -0.179 & -0.003 & $\mathbf{0 . 0 0 2}$ & $-\mathbf{0 . 0 0 5}$ \\
\hline C6 & -0.14 & -0.137 & -0.134 & -0.003 & -0.003 & 0 \\
\hline C7 & 0.279 & 0.32 & 0.331 & -0.041 & -0.011 & -0.03 \\
\hline C8 & 0.071 & 0.082 & 0.088 & -0.011 & -0.006 & -0.005 \\
\hline O1 & -0.545 & -0.463 & -0.428 & -0.082 & -0.035 & -0.047 \\
\hline C9 & -0.204 & -0.171 & -0.168 & -0.033 & -0.003 & -0.03 \\
\hline C10 & -0.166 & -0.129 & -0.121 & -0.037 & -0.008 & -0.029 \\
\hline C11 & 0.301 & 0.284 & 0.282 & 0.017 & 0.002 & 0.015 \\
\hline C12 & -0.156 & -0.151 & -0.116 & -0.005 & -0.035 & 0.03 \\
\hline C13 & -0.179 & -0.187 & -0.15 & 0.008 & -0.037 & 0.045 \\
\hline N1 & -0.408 & -0.317 & -0.225 & -0.091 & -0.092 & 0.001 \\
\hline N2 & -0.416 & -0.31 & -0.219 & -0.106 & -0.091 & -0.015 \\
\hline C14 & 0.304 & 0.268 & 0.28 & $\mathbf{0 . 0 3 6}$ & -0.012 & $\mathbf{0 . 0 4 8}$ \\
\hline C15 & -0.227 & -0.178 & -0.153 & -0.049 & -0.025 & -0.024 \\
\hline C16 & 0.03 & 0.013 & 0.012 & 0.017 & 0.001 & 0.016 \\
\hline C17 & 0.287 & 0.324 & 0.355 & -0.037 & -0.031 & -0.006 \\
\hline C18 & -0.177 & -0.172 & -0.157 & -0.005 & -0.015 & 0.01 \\
\hline C19 & -0.146 & -0.13 & -0.11 & -0.016 & -0.02 & 0.004 \\
\hline C20 & 0.555 & 0.585 & 0.624 & -0.03 & -0.039 & 0.009 \\
\hline O2 & -0.676 & -0.636 & -0.572 & -0.04 & -0.064 & 0.024 \\
\hline O3 & -0.566 & -0.532 & -0.498 & -0.034 & -0.034 & $1.110 \mathrm{E}-16$ \\
\hline O4 & -0.573 & -0.569 & -0.559 & -0.004 & -0.01 & 0.006 \\
\hline
\end{tabular}




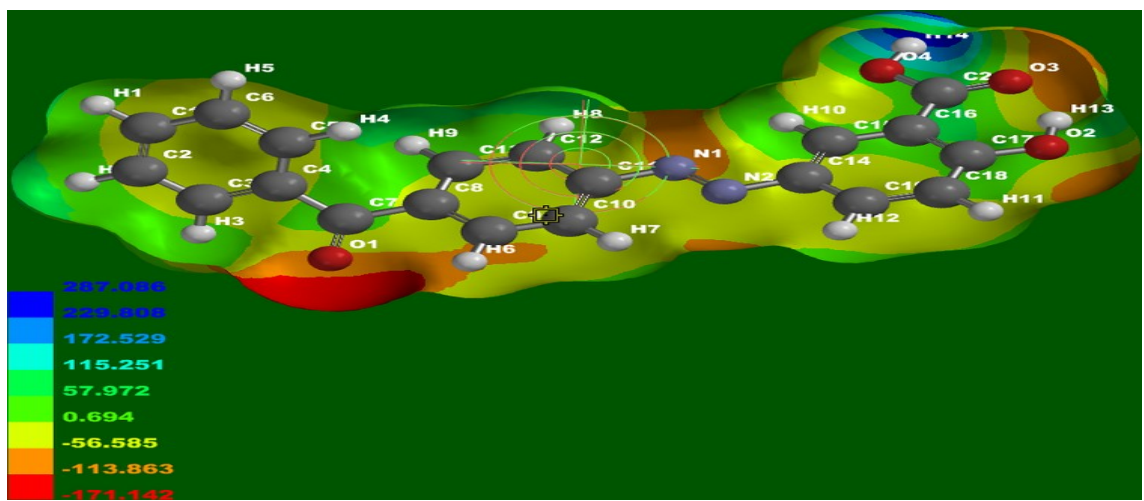

Figure 12d: Electrostatic potential map of AD4.

\section{CONCLUSIONS}

The corrosion inhibitive potential of benzoylphenyl)diazenyl)-2-hydroxybenzoic

(E)-5-((4acid (AD4) on mild steel in acidic medium was investigated. The inhibition efficiency increases with increased concentration of AD4 but decreases with increase in temperature. The inhibition is a spontaneous process that obeyed Langmuir isotherm. The result from the Tafel plot proved that the inhibitor is a mixed type inhibitor (cathodic and anodic inhibitor). From the calculated thermodynamic and kinetic parameters, AD4 adsorption followed the physiosorption mechanism. The results obtained from quantum chemical calculations agreed with the experiments. AD4 could be used in the oil, gas, and steel industry as anticorrosive agent.

\section{ACKNOWLEDGMENT}

We would like to thank Adeyemi College of Education and Adekunle Ajasin University for creating enabling environments for this research work.

\section{REFERENCES}

1. Society $A E$ and SF. Proceedings AESF SUR/FIN 2002: Annual International Technical Conference. In: Proceedings AESF SUR/FIN 2002: Annual International Technical Conference. 2002.

2. Verma C, Quraishi MA, Ebenso EE. Microwave and ultrasound irradiations for the synthesis of environmentally sustainable corrosion inhibitors: An overview. Sustain Chem Pharm [Internet]. 2018;10:134-47. Available from: https://doi.org/10.1016/j.scp.2018.11.001

3. Jadhav N, Kasisomayajula S, Gelling VJ. Polypyrrole/Metal Oxides-Based Composites/Nanocomposites for Corrosion Protection. Front Mater. 2020;7:1-7.
4. Albrakaty RH, Wazzan NA, Obot IB. Theoretical Study of the Mechanism of Corrosion Inhibition of Carbon Steel in Acidic Solution by 2aminobenzothiazole and 2- Mercatobenzothiazole. Int J Electrochem Sci. 2018;13:3535-54.

5. Amoko SJ, Akinyele OF, Oyeneyin OE, Olayanju DS, Aboluwoye CO. Experimental and theoretical investigation of corrosion inhibitive potentials of (E)4-hydroxy-3-[(2,4,6-tribromophenyl)diazenyl]

benzaldehyde on mild steel in acidic media. Phys Chem Res. 2020 Jun 1;8(3):399-416.

6. Fouda AS, Abdallah M, Eissa M. Corrosion inhibition of Aluminum in $1 \mathrm{M}$ phosphoric acid solutions using some Chalcones derivatives and synergistic action with halide ions. African J Pure Appl Chem. 2013;7(12):394-404.

7. Yao N, Diki S, Gondo G, Diomandé D, Akpa SJ, Ouédraogo A. Aluminum Corrosion Inhibition by 7( Ethylthiobenzimidazolyl ) Theophylline in 1M Hydrochloric Acid : Experimental and DFT Studies. Int J Appl Pharm Sci Res. 2018;3(4):41-53.

8. Oyeneyin OE, Obadawo BS, Ojo FK, Akerele DD, Akintemi EO, Ejelonu BC, et al. Experimental and Theoretical Study on the Corrosion Inhibitive Potentials of Schiff Base of Aniline and Salicyaldehyde on mild steel in $0.5 \mathrm{M} \mathrm{HCl}$. Adv J Chem B [Internet]. 2020;2(4):197-208. Available from: http://www.ajchem-b.com/

9. Ogunyemi BT, Latona DF, Adejoro IA. Molecular modeling and quantitative structure - property relationships (QSPRs) of purine derivatives as corrosion inhibitor in acid medium. Sci African [Internet]. 2020;8:e00336. Available from: https://doi.org/10.1016/j.sciaf.2020.e00336

10. Nwankwo HU, Olasunkanmi LO, Ebenso EE. Electrochemical and Computational Studies of Some Carbazole Derivatives as Inhibitors of Mild Steel Corrosion in Abiotic and Biotic Environments. J BioTribo-Corrosion [Internet]. 2018;4(13):1-17. 
Available from: https://doi.org/10.1007/s40735-0180130-7

11. Abboud $Y$, Abourriche $A$, Saffaj $T$, Berrada $M$, Charrouf M, Bennamara A, et al. A novel azo dye, 8quinolinol-5-azoantipyrine as corrosion inhibitor for mild steel in acidic media. Desalination [Internet]. 2009;237(1-3):175-89. Available from: http://dx.doi.org/10.1016/j.desal.2007.12.031

12. Mallikarjuna NM, Keshavayya J, Prasanna BM, Praveen BM, Tandon HC. Synthesis, Characterization, and Anti-corrosion Behavior of Novel Mono Azo Dyes Derived from 4,5,6,7Tetrahydro-1,3-benzothiazole for Mild Steel in Acid Solution. J Bio- Tribo-Corrosion [Internet]. 2020;6(1):1-17. Available from: https://doi.org/10.1007/s40735-019-0306-9

13. Amoko SJ, Akinyele OF, Oyeneyin OE, Olayanju DS, Aboluwoye CO. Synthesis, characterization and computational studies on the corrosion inhibitive potentials of ( e ) -3- ( 2-p-tolyldiazenyl ) -1nitrosonaphthalen-2-ol. Leonardo J Sci. 2018; (33):29-48.

14. Rbaa M, Dohare P, Berisha A, Dagdag $O$, Lakhrissi L, Galai M, et al. New Epoxy sugar based glucose derivatives as eco friendly corrosion inhibitors for the carbon steel in $1.0 \mathrm{M} \mathrm{HCl}$ : Experimental and theoretical investigations. J Alloys Compd [Internet]. 2020;833:154949. Available from: https://doi.org/10.1016/j.jallcom.2020.154949

15. Kumar A, Satya M, Tewari P. Density functional theory calculations of spectral, NLO, reactivity, NBO properties and docking study of Vincosamide $\mathrm{N}$ - Oxide active against lung cancer cell lines H1299. SN Appl Sci [Internet]. 2020;2:1021. Available from: https://doi.org/10.1007/s42452-0202842-9

16. M. Muthukkumar, T. Bhuvaneswari, G.Venkatesh, C.Kamal, P. Vennila, Stevan Armaković, Sanja J. Armaković, Y. Sheena Mary CYP. Synthesis, characterization and computational studies of semicarbazide derivative. J Mol Liq [Internet]. 2018; Available https://doi.org/10.1016/j.molliq.2018.09.123
17. Oyeneyin OE, Ajibade A, Esan TO. Substituent Effects on the Structural and Nonlinear Optical Properties of 1-[4-(\{(E)-[4(methylsulfanyl)phenyl]methylidene \}amino)phenyl] ethanone and Some of its Substituted Derivatives- a Theoretical Method. Phys Chem Res. 2018;6(3):66783.

18. Adejoro IA, Oyeneyin OE, Ogunyemi BT. Computational Investigation on Substituent and Solvent Effects on the Electronic, Geometric and Spectroscopic Properties of Azobenzene and Some Substituted Derivatives. Int J Comput Theor Chem. 2015;3(6):50-7.

19. AD B. Density - functional thermochemistry. III. The role of exact exchange. J Chem Phys. 1993;98:5648-52.

20. Shao Y, Molnar LF JY et al. SPARTAN 14', build 1.01. Irvine (CA); 2014.

21. Obot IB, Obi-egbedi NO, Umoren SA. Antifungal drugs as corrosion inhibitors for aluminium in $0.1 \mathrm{M}$ $\mathrm{HCl}$. Corros Sci [Internet]. 2009;51(8):1868-75. Available from:

http://dx.doi.org/10.1016/j.corsci.2009.05.017

22. Obot IB, Umoren S, Obi-egbedi NO. Corrosion inhibition and adsorption behaviour for aluminuim by extract of Aningeria robusta in $\mathrm{HCl}$ solution: Synergistic effect of iodide ions. J Mater Environ Sci. 2011;2(1):60-71.

23. Saliyan R. AA V. Inhibition of corrosion of mild steel in acid media by $\mathrm{N}^{\prime}$ - benzylidene-3-(quinolin-4ylthio) propanohydrazide. Bull Mater Sci. 2008;31(4):699-711.

24. Lukovits I., Kalman E. ZF. Corrosion Inhibitors: Correlation between the electronic structures and efficiency. Corros Sci. 2001;57(1):3-8.

25. Oyeneyin OE. Structural and Solvent Dependence of the Electronic Properties and Corrosion Inhibitive Potentials of 1,3,4-thiadiazole and Its Substituted Derivatives- A Theoretical Investigation. Phys Sci Int J. 2017;16(2):1-8. 


\section{SUPPLEMENTARY INFORMATION}

Corrosion Inhibitive Potentials Of (E)-5-((4-Benzoylphenyl)Diazenyl)-2Hydroxybenzoic Acid On Mild Steel Surface In 0.5 M HCl- Experimental and DFT Calculations

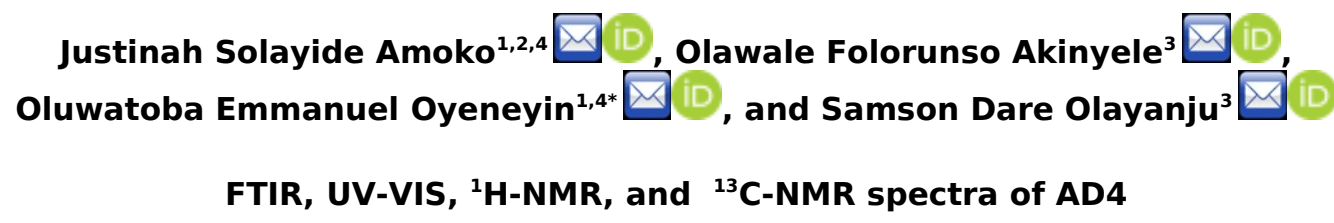

ФSHIMADZU

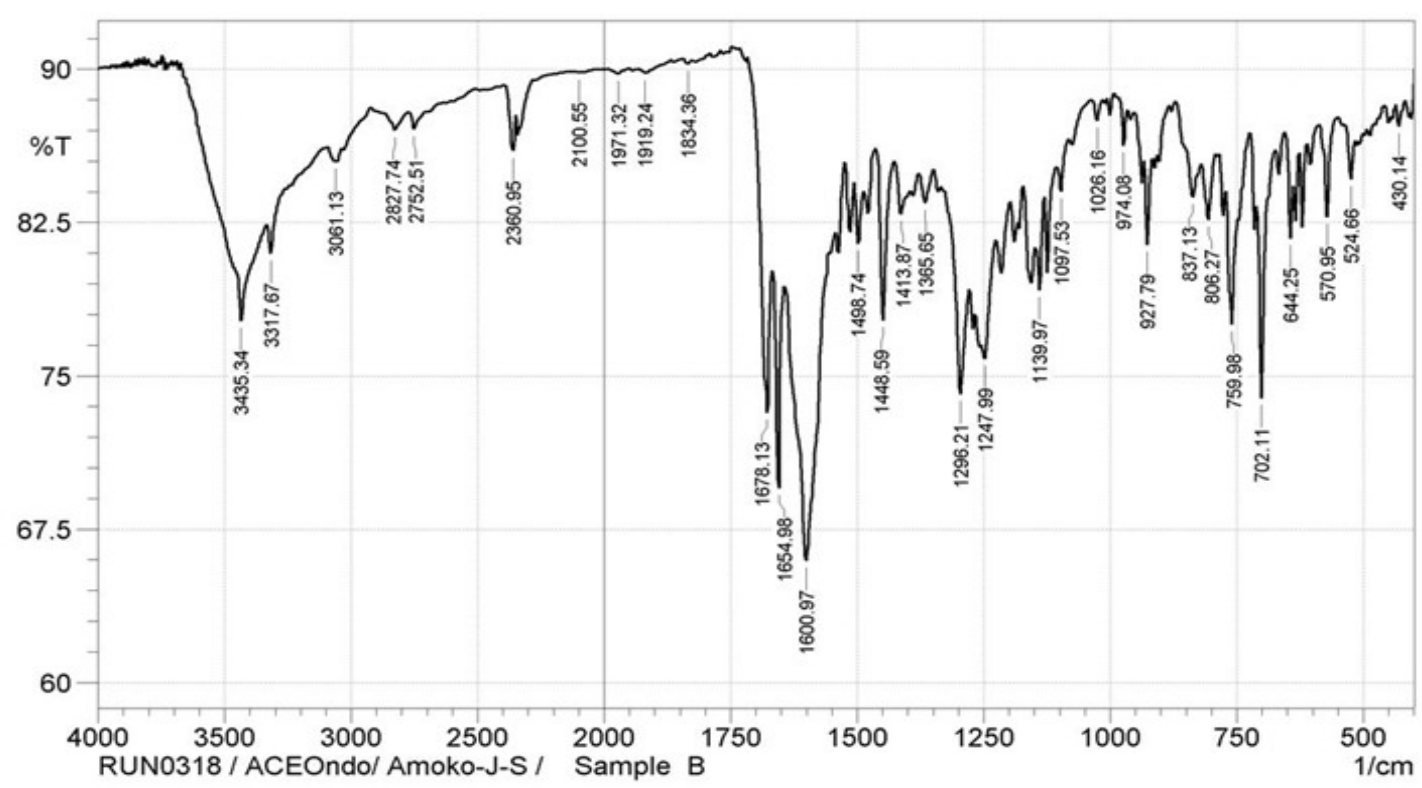

Figure S1: FTIR spectrum of AD4 


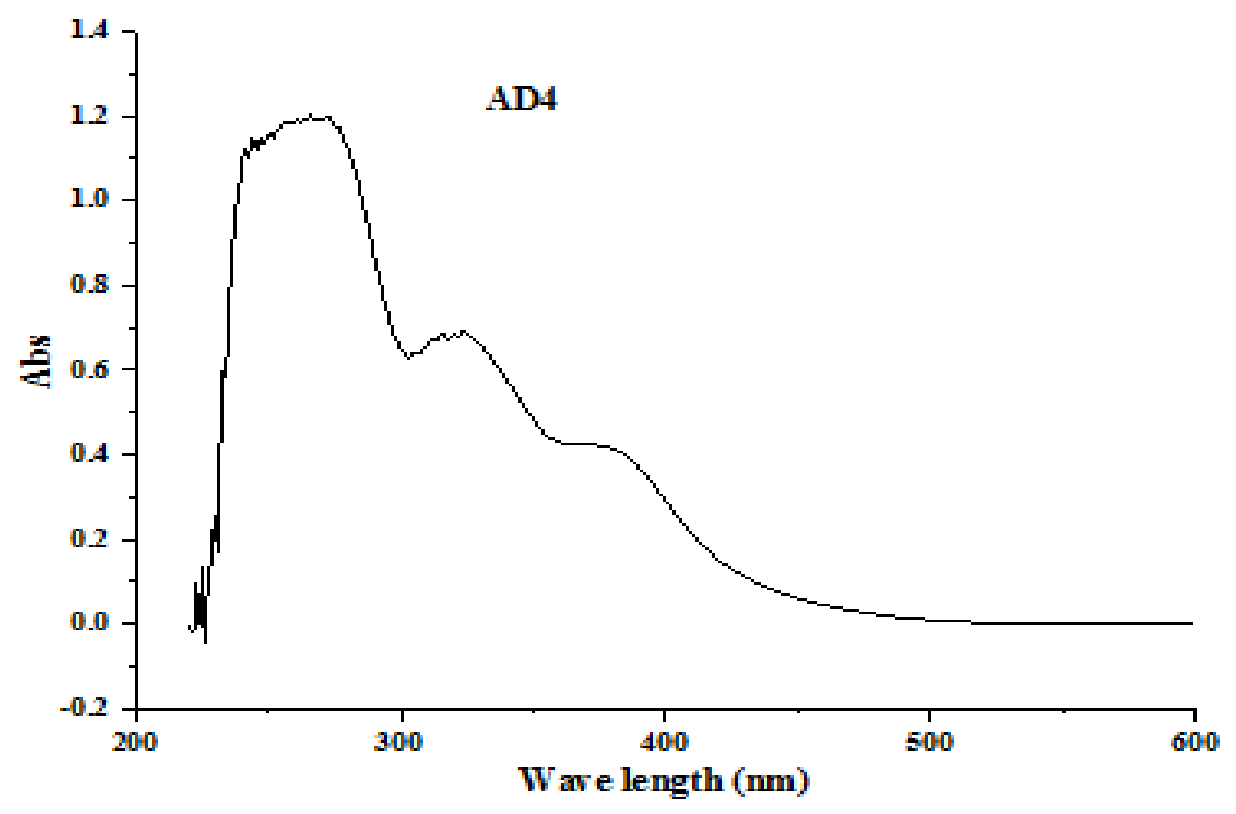

Figure S2: UV/Vis absorption spectrum of AD4

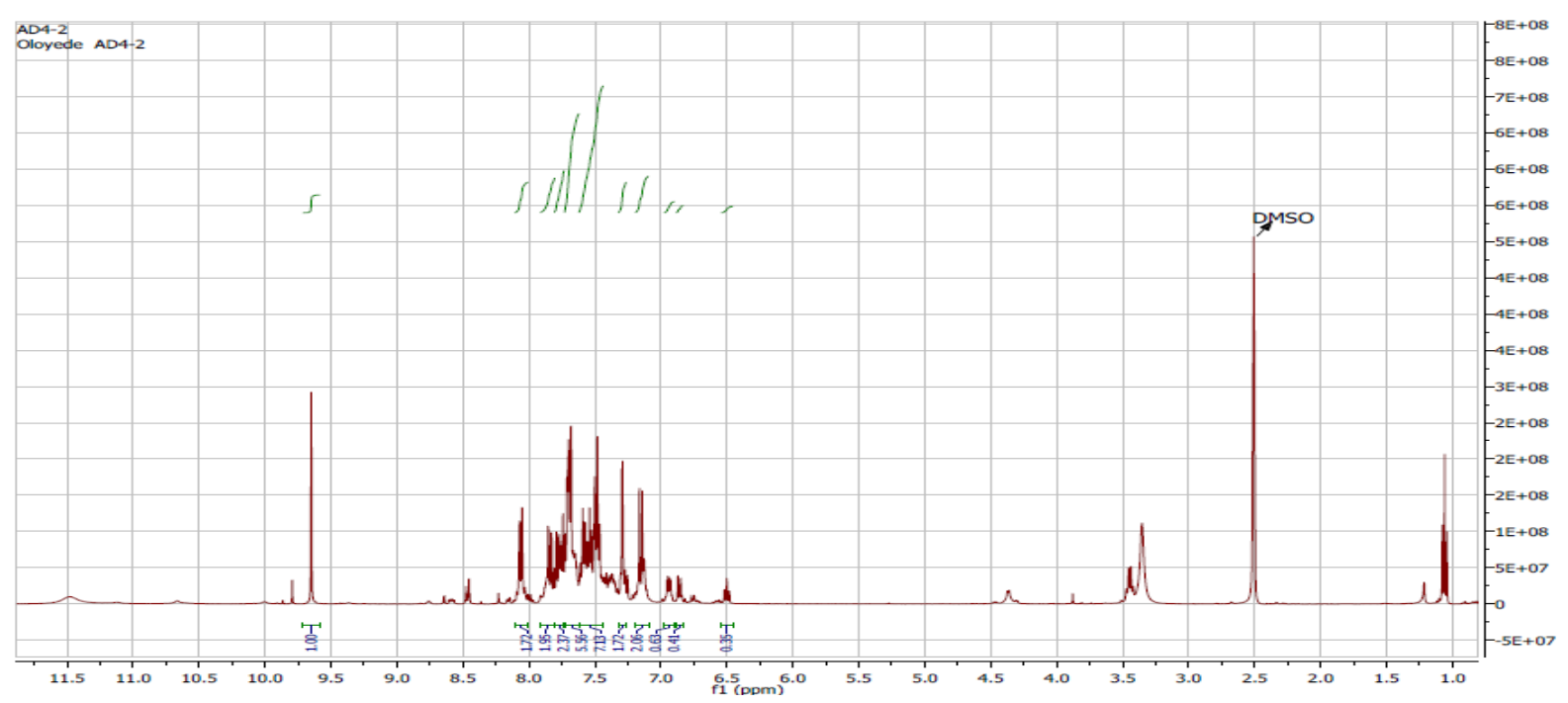

Figure S3: ${ }^{1}$ HNMR spectrum of AD4 


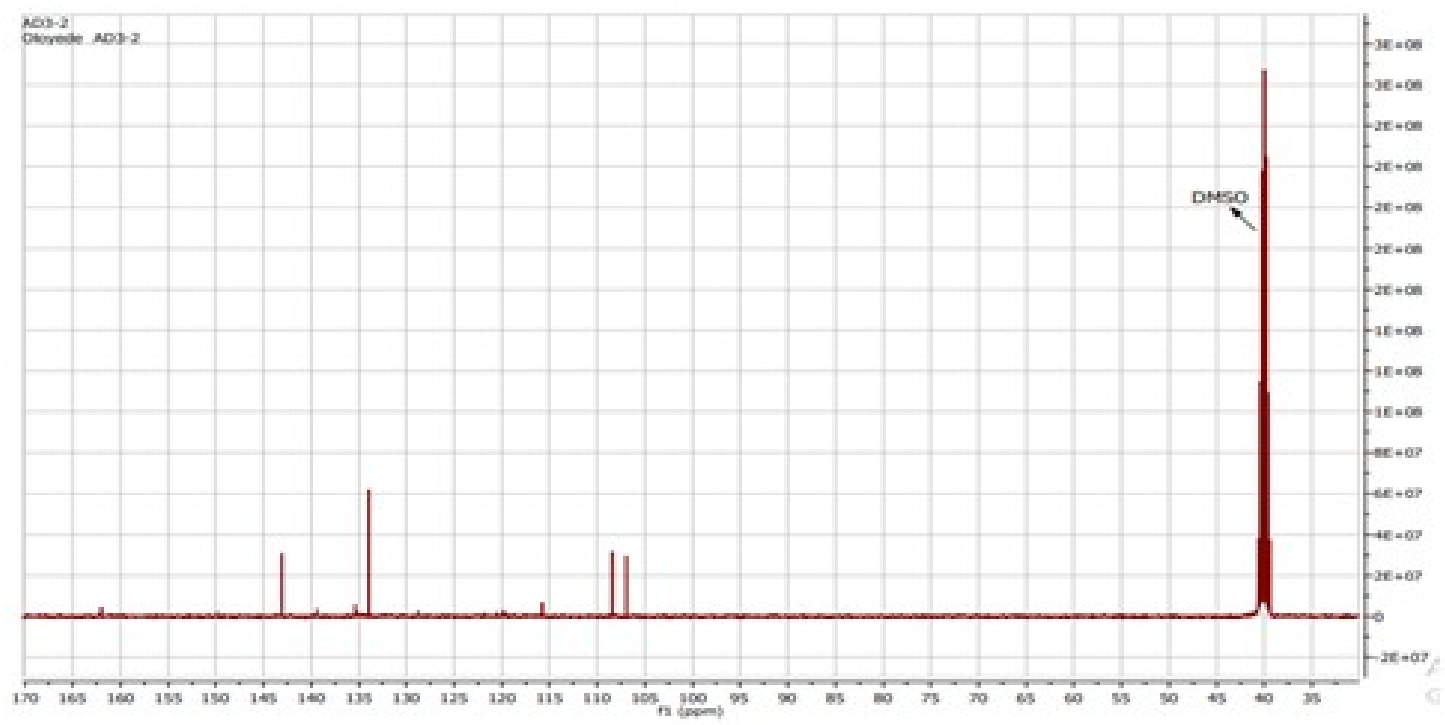

Figure S4: ${ }^{13} \mathrm{C}$-NMR spectrum of AD4 
